\title{
FIRST RECORD OF THE EVERMANN'S SNAKE EEL, OPHICHTHUS LITHINUS (ACTINOPTERYGII: ANGUILLIFORMES: OPHICHTHIDAE), FROM NORTHERN INDIAN OCEAN
}

\author{
Dipanjan RAY ${ }^{1}$, Anil MOHAPATRA ${ }^{1 *}$, Sudeepta BISWAS ${ }^{2}$, Kamala K. SATPATHY ${ }^{2}$, \\ and Subhrendu S. MISHRA ${ }^{3}$ \\ ${ }^{1}$ Marine Aquarium and Regional Center, Zoological Survey of India, Digha, West Bengal, India \\ ${ }^{2}$ EnSD, RSEG, EIRSG, IGCAR, Kalpakkam, Tamil Nadu, India \\ ${ }^{3}$ Marine Fish Section, Zoological Survey of India, Kolkata, India
}

Ray D., Mohapatra A., Biswas S., Satpathy K.K., Mishra S.S. 2015. First record of the Evermann's snake eel, Ophichthus lithinus (Actinopterygii: Anguilliformes: Ophichthidae), from northern Indian Ocean. Acta Ichthyol. Piscat. 45 (1): 89-93.

\begin{abstract}
A little known species of snake eel, Ophichthus lithinus (Jordan et Richardson, 1908), is reported for the first time from the east coast of India, Bay of Bengal based on two specimens 632 and $720 \mathrm{~mm}$ in total length, collected respectively at Digha, West Bengal and Kalpakam, Tamil Nadu, India. This is the first attempt to provide a detailed description of the species from the Indian Ocean. The presently reported findings constitute an extension of the known distributional range of this species from the Western Pacific to the eastern coast of India.
\end{abstract}

Keywords: new record, fish, West Bengal, Tamil Nadu, India, Bay of Bengal

The fishes of the family Ophichthidae, commonly known as snake eels and worm eels, comprise 59 genera, of which 45 are belonging to the subfamily Ophichthinae (tail tip hard, pointed and finless) (McCosker 1998, 1999, 2007) and 14 to the subfamily Myrophinae (tail tip flexible and confluent with dorsal and anal fins) (McCosker et al. 2012, Hibino et al. 2013), both comprising more than 260 species in the tropical and subtropical seas throughout the world (Castle and McCosker 1999, McCosker et al. 2012). Members of this family are associated with a variety of marine habitats such as sandy or muddy bottoms, middle water, and reefs at depths ranging usually from near shore to $100 \mathrm{~m}$; some are found even as deep as $1300 \mathrm{~m}$. The members of the family Ophichthidae are of great interest for ichthyologists due to their body shape, behaviour, colouration patterns, and distribution in diverse habitats. Many of these species occur only sporadically or are known from a single specimen. This is because of their peculiar tail-burrowing nature (many escape during sam- pling), nocturnal activity, and a specific habitat preference (Castle and McCosker 1999).

The aim of this study was to describe the morphological characteristics of a rare snake eel species - the Evermann's snake eel, Ophichthus lithinus (Jordan et Richardson, 1908), collected in West Bengal and Tamil Nadu, India. This species is reported herewith for the first time from the northern Indian Ocean.

Two specimens of snake eel, Ophichthus lithinus, were collected (Fig. 1), one (MARC/ZSI/F3330) of $720 \mathrm{~mm}$ in total length (TL) from Shankarpur fishing harbour, West Bengal, India caught by a commercial trawl at about 28 nautical miles from Digha coast of West Bengal, India $\left(21^{\circ} 06^{\prime} \mathrm{N}\right.$ and $\left.087^{\circ} 42^{\prime} \mathrm{E}\right)$ at about 31 meters of depth, on 7 November 2013 and another (ZSI F 10996/2) of $632 \mathrm{~mm}$ TL from the seawater screening system of the pump house of the cooling water system of the Madras Atomic Power Station (MAPS) located at Kalpakkam, Tamil Nadu, India $\left(12^{\circ} 33^{\prime} \mathrm{N}, 80^{\circ} 11^{\prime} \mathrm{E}\right)$, where the water is being pumped

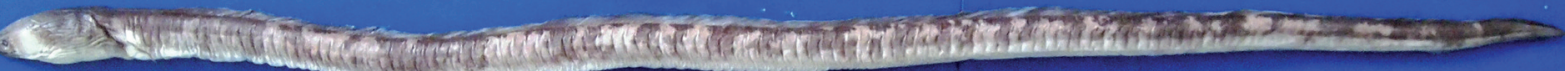

Fig. 1. Snake eel, Ophichthus lithinus, from Bay of Bengal, India (MARC/ZSI/F3330; TL = $720 \mathrm{~mm})$

\footnotetext{
* Correspondence: Dr. Anil Mohapatra, Marine Aquarium and Regional Center, Zoological Survey of India, Digha, West Bengal - 721 428, India, phone: (+91) 3220266310, e-mail: (AM) anil2k7@gmail.com, (DR) dipanjan2010@gmail.com, (SB) sudeepta.biswas@gmail.com, (KKS) satpathy_mfh@yahoo.com, (SSM) subhrendumishra@gmail.com.
} 
from 50 meters of depth (Biswas et al. 2010), collected in July 2008. The original coloration of live specimens was recorded on photographs. Taxonomic identification of the specimens was based on McCosker et al. (2012). Measurements and counts of the examined specimens follow Castle and McCosker (1999) and McCosker (2010); except the measurement of the lower jaw which was measured from the tip of lower jaw to mouth cleft. The presently illustrated specimen was deposited in the Museum of Marine Aquarium and Regional Center, Zoological Survey of India, Digha (MARC/ZSI/F3330) and the other specimen at the Fish Division, Zoological Survey of India, Kolkata (ZSI F 10996/2). Morphometric ratios and meristic counts of the second specimen (ZSI F 10996/2) are given in parentheses following that of the first specimen in the description section.

\section{OPHICHTHIDAE Rafinesque, 1815 Ophichthus Ahl, 1789}

Ophichthus lithinus (Jordan et Richardson, 1908)

Diagnosis. Uniserial teeth in jaws and vomer; unpointed and elongated pectoral fin; dorsal fin origin above middle part of pectoral fin; dorsal part of body with brown irregular blotches; ventral part pale; body depth less than 30 in total length (TL).

Detailed description. Body elongated, scaleless, stout and compressed in tail region; depth at gill opening 34.3 (34.2) in TL, depth at dorsal fin origin 34.7 (33.6) in TL, depth at anus 35.4 (35.4) in TL. Head 10.3 (10.0) in TL; branchial basket slightly wide and deep compared to body depth; head and trunk combined 1.9 (2.0) in TL; trunk 2.4 (2.5) in TL; tail 2.1 (2.0) in TL. Eye small and 11.2 (10.8) in head length (HL); snout long and overhanging lower jaw, 5.1 (5.3) in HL and 52.6 (52.7) in TL, underside of snout bisected by a groove flanking the anteriormost tooth. Maxilla reaching well behind eye, lower jaw included, upper and lower lips touch when mouth closed; upper jaw 3.1 (2.9) in HL, lower jaw 4.1 (3.8) in HL; eye 3.6 (3.7) in upper jaw; interorbital space 7.3 (7.0) in HL. Anterior nostril tubular and more or less half of eye diameter; posterior nostril labial. Gill opening 8.2 (8.4) in HL. Dorsal fin origin behind gill opening and middle of pectoral fin having 296 (294) rays, predorsal length 8.6 (8.8) in TL, dorsal fin base 1.1 (1.2) in TL; anal fin with 136 (135) rays; preanal length 1.9 (2.0) in TL; pectoral fin well developed with 11 rays and its length more or less equal to eye diameter, elongated and not pointed, its base 10.8 (10.5) in HL and length 3.9 (4.0) in HL; dorsal fin and anal fin ends short distance before tail tip which is very hard and pointed, fin less area of tail region 14.3 in HL. Head pore small (Fig. 2) and arrangements are: single temporal and interorbital pore, supraorbital pores $1+4$, infraorbital pores $2+3+2$, preoperculomandibular pores 8 (lower jaw pores 5, preopercular pores 3), lateral line pores small and difficult to count completely; numbers of lateral line pores until to pectoral fin origin 10; up to dorsal fin origin 13 and up to anus 69. Teeth strong but short (Fig. 3), conical and well separated from each other at base. Anterior part of maxilla with 4 teeth in rosette arrangement followed by sequence of: gap, two intermaxillary teeth, gap, 18 vomerine teeth in single row gradually decreasing in size. Maxillary teeth about 20, uniserial and equal in size. Mandibular teeth also uniserial, about 20 in number, first one very small but others equal in size. Specimen MARC/ZSI/F3330 having total vertebrae 151 with 11 pre-dorsal and 68 pre-anal vertebrae.

Colouration. In fresh specimens, dorsal surface of head and tail covered with brown irregular blotches ending

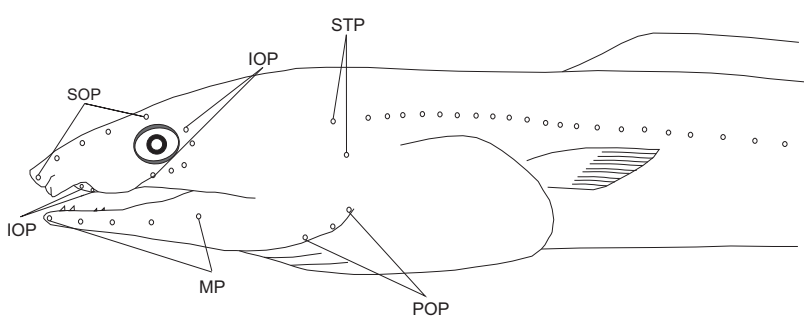

Fig. 2. Lateral view of head and head pores of snake eel, Ophichthus lithinus, from Bay of Bengal, India (MARC/ZSI/F3330; TL $=720 \mathrm{~mm}$ )
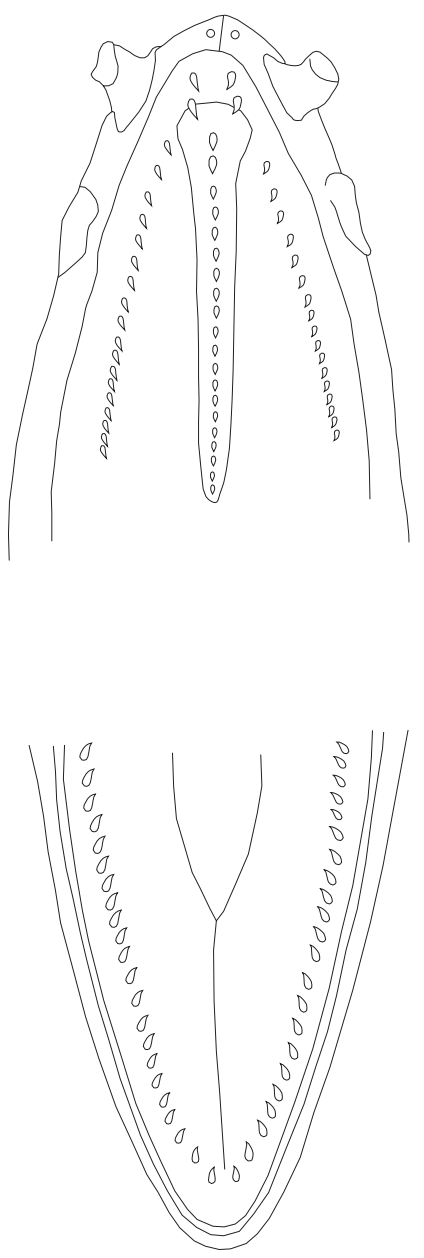

Fig. 3. Dentition on upper jaw and lower jaw of snake eel, Ophichthus lithinus, from Bay of Bengal, India (MARC/ZSI/F3330; TL $=720 \mathrm{~mm}$ ) 
before ventral surface; ventral region creamy white; dorsal portion of head and gill basket brown, posterior part of eye and gill opening to pectoral fin base pale; mandible and intermandibular region brown; dorsal fin pale and light brown in regular intervals, anal fin, pectoral fin, and tip of caudal fin pale.

Distribution. Ophichthus lithinus is known to occur in the Western Pacific region through Australia (Northern territory, Queensland, western Australia) (Froese and Pauly 2014), Philippines (Cuyo: Type locality of O. lithinus) (Froese and Pauly 2014), Taiwan (Taiwan Strait, Peng-hu island, South China sea) (Hoese et al. 2006), southern Japan (Masuda et al. 1984); Papua New Guinea (Torres Strait) (Kailola 1987), Vietnam (Gulf of Tonkin) (Nguyen and Nguyen 1994), Republic of Korea (Froese and Pauly 2014), and Hong Kong (South China Sea) (Ni and Kwok 1999), Kaohsiung, Taiwan - the type locality of the nominal species Ophichthus evermanni (Jordan and Richardson, 1909). The presently reported findings constitute the first record of $O$. lithinus from the eastern coast of India, Bay of Bengal (Fig. 4).

Remarks. The specimens described above bear a finless tail with a hardened tip, dorsal and anal ending well before tail tip; well developed pectoral fin, greater than gill opening, with restricted base; tube-like anterior nostril; entire upper lip; dorsal fin origin behind pectoral fin base; teeth conical, uniserial in jaws and vomer. These characters led us to place it in the genus Ophichthus.
In the Indian coastal waters, the family Ophichthidae is represented by 16 genera and 24 species (Biswas et al. 2010). Of which, Ophichthus lithinus (Jordan et Richardson, 1908) is very similar in appearance to Brachysomophis cirrocheilos (Bleeker, 1857), but the later species differs in having barbels (cirri) on both lips and jaws are more or less equal in size $(O$. lithinus possess a lower jaw shorter than the upper jaw) (Fig. 5); higher number of vertebrae, and in its colouration and the pectoral fin size and shape. O. lithinus is similar in colouration on its head region with

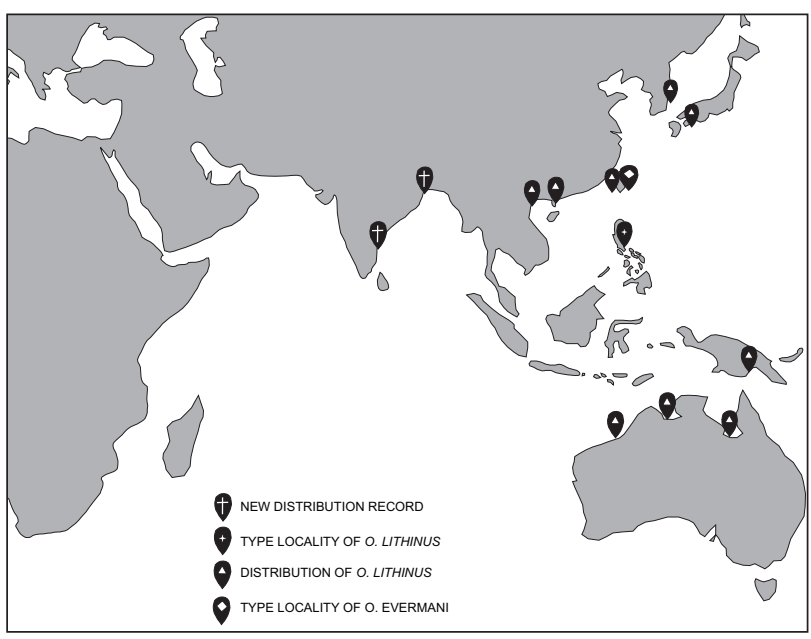

Fig 4. Distribution of snake eel, Ophichthus lithinus (covering junior synonym $O$. evermani)
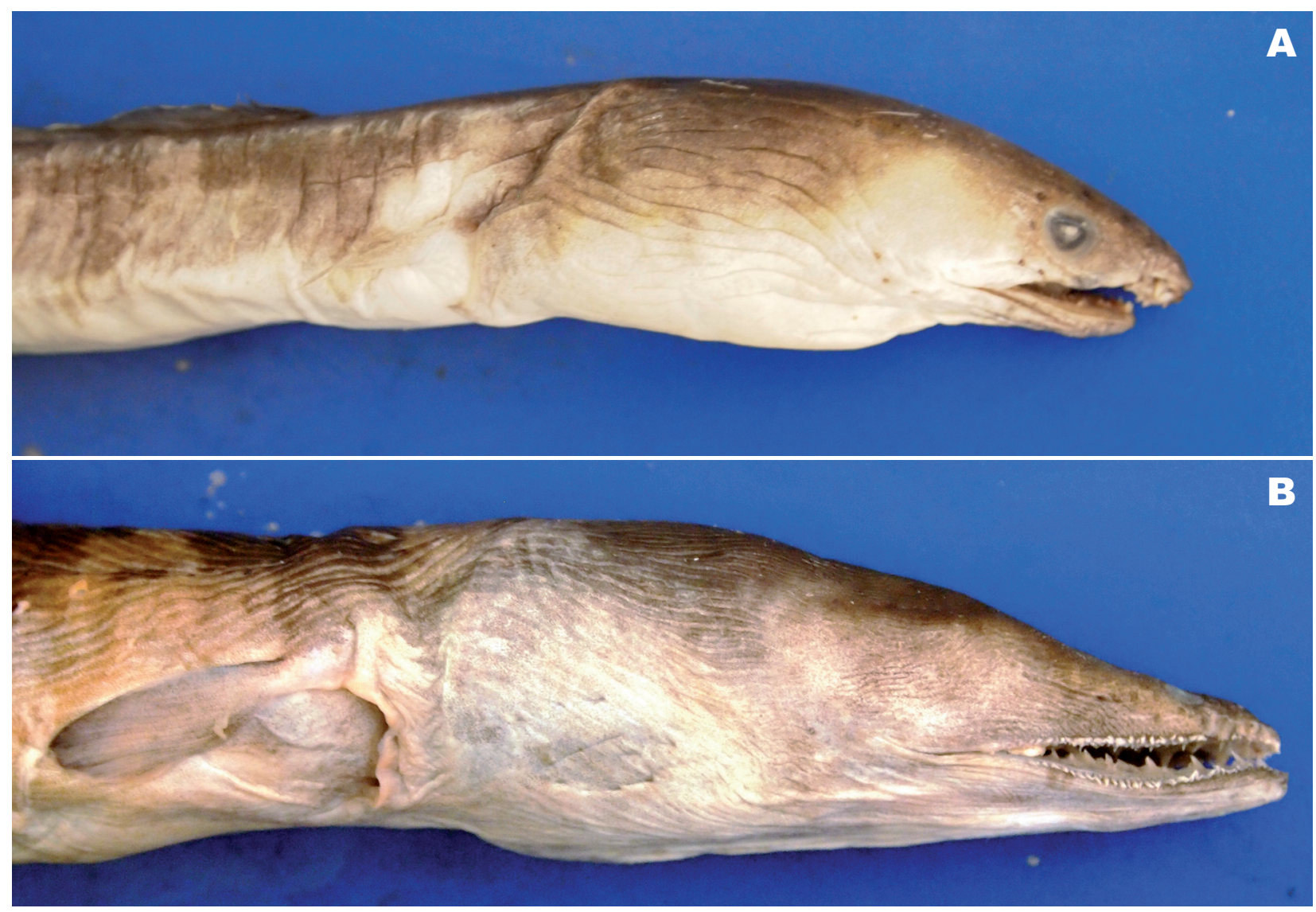

Fig. 5. Lateral view of head and mouth of snake eels from, India: A, Ophichthus lithinus, specimen from Bay of Bengal (MARC/ZSI/F3330; TL = 720 mm); B, Brachysomophis cirrocheilos $(\mathrm{MARC} / \mathrm{ZSI} / \mathrm{F} 3318 ; \mathrm{TL}=875 \mathrm{~mm})$ 
Ophichthus cephalozona Bleeker, 1864, but the latter has a body depth of 24-30 in TL (more than 30 in O. lithinus) and the colour of the trunk and tail region is distinctly different in having prominent brown patches present on trunk and tail in O. lithinus but lacking in O. cephalozona. Other species of the genus known from this region do not possess any such colour pattern and are rather plain brownish or yellowish brown.

The genus Ophichthus is known to have about 75 species worldwide (Froese and Pauly 2014). The majority of these species have uniform body colouration, while others have distinct dark saddles or spotted. The characteristic dorsal surface of trunk and tail overlain with brown irregular blotches and distinctly pale ventral surface of Ophichthus lithinus separates it from other congeners.

Ophichthus lithinus was described by Jordan and Richardson (1907*) as Leiuranus lithinus based on of one specimen from Cuyo, Philippines. Jordan and Richardson (1909) described Ophichthus evermanni based on two specimens from Kaohsiung, Taiwan, which was later treated as a junior synonym of $O$. lithinus (see Hoese et al. 2006, Ho and Shao 2011). In both the cases the descriptions given for this species were inadequate. Although we could not examine the holotype, the comprehensive key for Japanese Ophichthus provided by McCosker et al. (2012) was good enough to distinguish the specimens of O. lithinus from its congeners, but a proper description of the species is still lacking. Hence, an attempt has been made in this paper to provide a detailed description of the species with morphometric characters and meristic counts. The meristic values of $O$. lithinus of the presently reported study match well those of the holotype in the original description.

The presently reported study also features a geographical range extension of Ophichthus lithinus from the Western Pacific to the east coast of India and an addition to the ichthyofaunal diversity of Indian coastal waters.

\section{ACKNOWLEDGEMENTS}

We thank Dr. K. Venkataraman, Director, Zoological Survey of India for supporting this work, Dr. David G. Smith (Smithsonian Institution, Washington DC, USA), Dr. John E. McCosker (California Academy of Sciences, San Francisco, USA), and Dr. Hsuan-Ching Ho (National Museum of Marine Biology and Aquarium, Taiwan) for their valuable help in providing specific literature and suggestions in an early version of the manuscript. The third and fourth authors are grateful to the Director of IGCAR for the support. First author thanks the Zoological Survey of India for financial support. Special thanks to Mr. Rasmi Ranjan Mahapatra, Senior Geologist, Geological Survey of India for his help in the preparation of map.

\section{REFERENCES}

Biswas S., Mishra S.S., Satpathy K.K., Selvanayagam M. 2010. First record of stargazer snake eel Brachysomophis cirrocheilos (Osteichthyes: Ophichthidae) from India.
Marine Biodiversity Records 3: e85. DOI: $10.1017 / \mathrm{S} 1755267210000795$

Castle P.H.J., McCosker J.E. 1999. A new genus and two new species of myrophine worm-eels, with comments on Muraenichthys and Scolecenchelys (Anguiliformes: Ophichthidae). Records of Australian Museum 51 (2): 113-122.

Hibino Y., McCosker J.E., Kimura S. 2013. Redescription of a rare worm eel, Muraenichthys macrostomus Bleeker 1864, a senior synonym of Skythrenchelys lentigenosa Castle and McCosker 1999 (Anguilliformes: Ophichthydae: Myrophinae). Ichthyological Research 60 (3): 227-231.

DOI: $10.1007 / \mathrm{s} 10228-013-0337-\mathrm{Z}$

Ho H.-C., Shao K.-T. 2011. Annotated checklist and type catalog of fish genera and species described from Taiwan. Zootaxa 2011 (2957): 1-74.

Hoese D.F., Bray D.J., Paxton J.R., Allen G.R. (eds.) 2006. Fishes. In: Beesley O.L., Wells A. (eds.) Zoological catalogue of Australia. Australian Biological Resources Study and CSIRO Publishing, Collingwood No. 35.3. Vols. 1-3.

Froese R., Pauly D. (eds.) 2014. FishBase. [version 02/2014] http://www.fishbase.org

Jordan D.S., Richardson R.E. 1907. [Published in 1908] in Fishes from islands of the Philippine Archipelago. Bulletin of the Bureau of Fisheries 27: 233-287.

Jordan D.S., Richardson R.E. 1909. A catalogue of the fishes of the island of Formosa, of Taiwan, based on the collections of Dr. Hans Sauter. Memoirs of the Carnegie Museum 4 (4): 159-204.

Kailola P.J. 1987. The fishes of Papua New Guinea. A revised and annotated checklist. Vol. 1. Myxinidae to Synbranchidae. Research Bulletin No. 41. Department of Fisheries and Marine Resources, Port Moresby, Papua New Guinea.

Masuda H., Amaoka K., Araga C., Uyeno T., Yoshino T. (eds.) 1984. The fishes of the Japanese Archipelago. Vol. 1. Tokai University Press, Tokyo, Japan.

McCosker J.E. 1998. Snake-eels of the genus Xyrias (Anguilliformes: Ophichthidae). Cybium 22 (1): 7-13.

McCosker J.E. 1999. Pisces Anguilliformes: Deepwater snake eels (Ophichthidae) from the New Caledonia region, Southwest Pacific Ocean. In: Crosnier A. (ed.) Résultats des Campagnes MUSORSTOM. Mémoires du Muséum national d'Histoire naturelle (N. S.) (Série A) Zoologie 20 (180): 571-588.

McCosker J.E. 2007. Luthulenchelys heemstraorum, a new genus and species of snake eel (Anguilliformes: Ophichthidae) from KwaZulu-Natal, with comments on Ophichthus rutidoderma (Bleeker, 1853) and its synonyms. Smithiana Bulletin 2007 (7): 3-7.

McCosker J.E. 2010. Deepwater Indo-Pacific species of the snake-eel genus Ophichthus (Anguilliformes: Ophichthidae), with the description of nine new species. Zootaxa 2010 (2505): 1-39.

McCosker J.E., Ide S., Endo H. 2012. Three new species of ophichthid eels (Anguilliformes: Ophichthidae) from Japan. Bulletin of the National Museum of Nature and Science, Series A, Zoology, Supplement 6: 1-16.

\footnotetext{
* The species description date (1908) is the date of effective publication of the paper.
} 
Nguyen H.P., Nguyen N.T. 1994. Checklist of marine fishes in Vietnam. Vol. 2. Osteichthyes, from Elopiformes to Mugiliformes. Science and Technics Publishing House, Hanoi, Vietnam.

Ni I.-H., Kwok K.-Y. 1999. Marine fish fauna in Hong Kong waters. Zoological Studies 38 (2): 130-152.
Received: 16 June 2014

Accepted: 11 November 2014

Published electronically: 31 March 2015 